\title{
La influencia legislativa de la oposición en las iniciativas de los gobiernos en minoría en México, 1997-2012
}

\author{
The legislative influence of the opposition in the \\ initiatives of the minority governments in Mexico, \\ 1997-2012
}

\section{Carlos Vázquez Ferrel*}

Perfiles Latinoamericanos, 27(54) | 2019

DOI: $10.18504 / \mathrm{pl} 2754-006-2019$

Recibido: 28 de septiembre de 2016

Aceptado: 15 de febrero de 2019

\section{Resumen}

Los estudios sobre la dinámica de los gobiernos en minoría en sistemas presidenciales son escasos a pesar de su frecuencia en América Latina. Este trabajo analiza la influencia legislativa de la oposición —entendida como las enmiendas que ella impulsa — sobre las iniciativas de los presidentes de los gobiernos mexicanos en minoría del periodo 1997-2012. Se argumenta que uno de los mecanismos que viabilizaron la aprobación de piezas de la agenda legislativa de los presidentes fue, precisamente, la participación activa de legisladores de oposición en el contenido final de estas iniciativas. A partir de una base de datos original — que capta la magnitud de cambio que implica cada enmienda - se muestra la influencia legislativa de la oposición, que se revela intensa y variante. Son puestos en juego dos modelos analítico-explicativos para identificar los factores que incrementan la probabilidad de que varíe esta influencia legislativa, la cual se encuentra pautada por modificaciones en el sistema de partidos y la dinámica político-contextual.

Palabras clave: oposición, Congreso, presidente, gobierno en minoría, enmiendas, sistemas presidenciales.

\begin{abstract}
Studies about the dynamics of minority governments in presidential systems are limited, even though it is a frequent reality in Latin America. This work focuses on the legislative influence of the opposition — which is understood as the amendments exerted by these groups—, in the initiatives of the presidents of the Mexican minority governments (1997-2012). It is argued that one of the mechanisms that enabled the approval of pieces of the presidents' legislative agenda was, precisely, the active participation of the opposition legislators in the final content of these initiatives. An original database - that captures the magnitude of change of each amendment - reveals the intense and variant legislative influence of the opposition at the parliament. Two analytic models are put into play to identify the factors that increase the probability for this legislative influence to vary, which is shaped by the changes in the political parties system and the political contextual dynamics.
\end{abstract}

Keywords: opposition, Congress, president, minority government, amendments, presidential systems.

* Doctor en Ciencia Política por la Universidad de Salamanca (España). Profesor-Investigador en el Instituto Tecnológico y de Estudios Superiores de Monterrey (México) | carlos.vazquez820308@gmail.com 


\section{Introducción}

E con otros tempranos esfuerzos, subrayó las dificultades institucionales que enfrentan los sistemas presidenciales para forjar una relación constructiva entre poderes. Posteriormente, Mainwaring \& Shugart (2002a) pusieron de relieve la "difícil combinación" entre sistemas presidenciales y multipartidismo ya que, además de incrementar las probabilidades de que el presidente se encuentre en minoría, también fomentaría la polarización y podría generar choques directos entre fuerzas políticas rivales. Sin embargo, a la fecha, la sostenibilidad de las democracias presidenciales multipartidistas en América Latina se encuentra libre de disputas (Raile, Pereira \& Power, 2010). Esta realidad — que desafía las predicciones de la primera generación de trabajos — ha concitado la aparición de múltiples interrogantes e investigaciones que buscan explicar los modos y funcionalidades de tal relación. El objetivo del presente artículo es explorar la relación legislativa de la oposición que viabiliza la agenda impulsada en el Congreso por un presidente en minoría, esto a la luz del caso mexicano. Se explora en concreto la influencia legislativa de la oposición, entendida esta como las enmiendas efectuadas a las iniciativas del Ejecutivo, como parte de los beneficios que ella obtiene por colaborar en su aprobación.

En los sistemas presidenciales multipartidistas, hay agrupaciones de oposición que adoptan diversas estrategias legislativas para relacionarse con el Ejecutivo. Una de estas consiste en abandonar el bloque opositor para integrarse a un gobierno de coalición multipartidista que genere en el Congreso un apoyo legislativo estable mayoritario al presidente al estilo de las coaliciones europeas en sistemas parlamentarios (Deheza, 1998; Morgenstern, Negri \& Pérez-Liñán, 2008). Chasquetti (2008), por ejemplo, señala que de 1978 a 2007, el 60.5\% de los gobiernos electos se encontraba en condiciones minoritarias en el Congreso. Sin embargo, al inicio de sus mandatos diversos presidentes revirtieron esa condición, ya que el 61\% logró consolidar una posición mayoritaria mediante la incorporación de múltiples partidos en una coalición gobernante que previamente eran parte de la oposición.

Otra estrategia legislativa de las agrupaciones de oposición para relacionarse con el Ejecutivo es la de mantener una relación interactiva que oscila entre la colaboración y la confrontación. Morgenstern, Negri \& Pérez-Liñán (2008) han hallado que de 1980 a 2004 en dieciocho países de América Latina el $52 \%$ fueron gobiernos unipartidistas minoritarios que se vieron obligados a forjar coaliciones ad hoc para la aprobación de sus proyectos de ley. Por su parte, Strøm (1991, p. 42), con base en su análisis sobre el funcionamiento de 
los gobiernos europeos en minoría, apunta que "el estudio de los Parlamentos demuestra que los partidos que no están en el gobierno podrían beneficiarse significativamente influenciando las políticas”. ¿Cómo influyen los partidos políticos de oposición en el Congreso sobre las políticas gubernamentales en sistemas presidenciales multipartidistas?

Además de que son escasos los estudios sistemáticos sobre el rol legislativo de la oposición en gobiernos en minoría bajo sistemas presidenciales multipartidistas, las características del sistema de partidos mexicano lo hacen un caso atractivo para aproximarse al funcionamiento de estas agrupaciones en su relación legislativa con el Ejecutivo. Entre 1997 y 2012 la actividad en el Congreso mexicano ha estado marcada por dos condiciones: ningún presidente del país ha contado con mayoría partidista legislativa estable afín y la representación legislativa del conjunto de las agrupaciones de oposición —cohesionada en dos partidos - es mayor que la del partido del presidente, en tanto que en lo individual los dos principales partidos de oposición tienen un tamaño legislativo semejante al del partido en el gobierno. En consecuencia, el apoyo de por lo menos uno de los partidos de oposición resulta indispensable para que el gobierno ponga en marcha sus políticas. A pesar de que esta realidad podría llevarlos a obstruir sistemáticamente la agenda legislativa del Ejecutivo, ello no ha ocurrido, pero sí ha provocado que los presidentes mexicanos sean extremadamente cuidadosos en las negociaciones con los partidos de oposición en el Congreso de tal modo que puedan atraerse su apoyo e impulsar exitosamente la aprobación de sus iniciativas (Casar, 2013).

¿Por qué los partidos de oposición optarían por apoyar la aprobación de las políticas del Ejecutivo cuando más bien se beneficiarían de los fracasos legislativos de este? Las agrupaciones de oposición colaborarían con el gobierno como consecuencia de sus cálculos racionales. Strøm (1991) y Müller \& Strøm (1999) demostraron que los liderazgos partidistas de oposición básicamente construyen su relación legislativa sobre dos premisas: i) mediante una modalidad policyseeking, es decir, cumpliendo una parte de su oferta programática aunque no hayan obtenido el gobierno, para así buscar satisfacer en alguna medida a su núcleo de votantes y ampliar sus bases de apoyo político, y ii) mediante la vía vote-seeking, que los lleva a priorizar la maximización de votos y a implementar estrategias de confrontación y contraste con el gobierno, si ello incrementara sus votos. Una estrategia en el corto plazo de los partidos de oposición sería acercarse a la esfera gubernamental para influir en el contenido de las políticas del Ejecutivo para satisfacer y buscar expandir sus bases de apoyo político. Alternativa que sería balanceada con otra que los llevaría a una confrontación directa con el gobierno, teniendo siempre en mente los riesgos de fugas de votos y las oportunidades de su maximización. 
Este artículo se propone como un marco analítico tentativo para aproximarse a la influencia legislativa de la oposición —es decir, a las enmiendas impulsadas por estos grupos - en las iniciativas del Ejecutivo en los gobiernos en minoría en México. ${ }^{1}$ Dicho marco, además de que pretende identificar los factores que incrementan las probabilidades de que se efectúe una determinada enmienda, se conforma de dos modelos analíticos. El primero de estos incorpora variables relativas al sistema de partidos en el Congreso, en específico los representados en la Cámara de Diputados, tales como número efectivo de partidos, la fortaleza de la oposición, proximidad ideológica entre partidos, y la representación de partidos de oposición en las comisiones legislativas, lo que reflejaría los cambios en la composición y fortaleza de la oposición. Mientras que el segundo modelo capta los cambios en la dinámica político-contextual donde se desenvuelven los agentes partidistas.

El artículo se organiza en cinco secciones más esta introducción y unas consideraciones finales. En el apartado que sigue se revisa la literatura que ha explorado la relación legislativa entre oposición y gobiernos de minoría enfatizando en los factores que inciden positivamente en su colaboración, un contexto proclive a la influencia de la oposición en la agenda del Ejecutivo. Posteriormente, se da una breve contextualización del caso mexicano justificando su idoneidad para este análisis y se describe la operacionalización de la variable dependiente, es decir, de las enmiendas efectuadas. Este análisis se da a través de una dimensión centrada en el contenido la cual capta la magnitud del cambio que implica cada enmienda. En una sección subsiguiente se presentan la operacionalización, indicadores e hipótesis de ambos modelos. Para continuar después con la reseńa de los datos recabados y los resultados de los modelos sujetos a análisis. Finalmente, se discuten estos resultados destacándolos en su relevancia teórica y respecto al caso mexicano.

1 En este trabajo se utiliza el término gobierno en minoría y no gobierno dividido, aplicado para el caso mexicano por Casar (2002), Lujambio (1996) y (Weldon, 2002), entre otros. La noción de gobierno dividido se origina en la descripción del caso estadounidense, con un sistema bipartidista. Ello implica que cuando el partido del presidente no tiene mayoría en alguna de las Cámaras o en el Congreso, el partido opositor cuenta con ella y por esto controla el Congreso. Es decir, los gobiernos divididos se refieren a que "diferentes partidos controlan diferentes ramas de gobierno" (Powell, 1991, p. 231). O bien a que "un partido controla la presidencia y el otro partido controla una cámara o las dos del Congreso" (Pfiffner, 1992). Pero en una realidad con más de dos partidos esto no siempre ocurre, ya que es posible - como pasa en México con tres partidos- que ninguno cuente con la mayoría en el Congreso y en consecuencia ninguno lo controle. Por eso el concepto gobierno en minoría, que alude a la situación en la que se encuentra el partido del presidente en el Congreso, sería más preciso. 


\section{Revisión de la literatura}

Hasta hace no mucho tiempo era común referirse a los Congresos en América Latina como "sellos de goma", frase que aludía a la subordinación de esta institución para cumplir con lo que el presidente dictaba (Mezey, 1979), juicio que fue después matizado para revalorarla como "reactiva", es decir, que si bien el Ejecutivo seguía siendo un actor legislativo clave, los parlamentos en la región reaccionan modificando el contenido de los proyectos de ley impulsados por el presidente, forzando negociaciones o directamente rechazándolos (Cox \& Morgenstern, 2001). Incluso, Scartascini, Stein \& Tommasi (2010) hacen que se los identifique con una visión extrema de "callejones sin salida" para las reformas modernizadoras que los presidentes han promovido en América Latina.

Estas lecturas contrapuestas reflejan las complejidades de la relación entre el Congreso y el Ejecutivo, lo que ha impulsado el desarrollo de múltiples investigaciones sobre el tema (Amorim, 2006; Amorim, Cox \& McCubbins, 2003; Amorim \& Santos, 2012; García, 2009; Mustapic \& Goretti, 2012; Siavelis, 2003). No obstante, a pesar de los notables avances, la mayor parte de los estudios se ha concentrado en identificar las condiciones en que cobra efectividad el funcionamiento de los gobiernos multipartidistas asemejándose a los gobiernos de coalición surgidos en sistemas parlamentarios, de tal modo que el interés por explorar con mayor detalle el funcionamiento de los gobiernos en minoría bajo sistemas presidenciales multipartidistas ha sido bajo y se les ha percibido como débiles y muestra de la falta de destreza por parte de los agentes políticos para construir una relación legislativa confiable y efectiva (Figueiredo, Vieira \& Canello, 2012).

En su influyente trabajo sobre los gobiernos en minoría en sistemas parlamentarios, Strøm (1991) dejó en claro que estos no son una anomalía en Europa y subrayó tres puntos sobre la lógica racional de su funcionamiento: $i$ ) en determinados contextos los liderazgos partidistas priorizan la puesta en marcha de políticas públicas y la defensa e impulso de intereses concretos, por sobre la opción de conformar una coalición formal y estable de apoyo al gobierno; ii) esto se da porque se tienen expectativas de poder reclamar públicamente créditos de triunfos programáticos o haber bloqueado políticas gubernamentales indeseadas, para fortalecer así los lazos de estos liderazgos con sus bases de apoyo político y sus votantes, y iii) de esta forma surge una oposición legislativa que oscila entre la colaboración puntual, la no colaboración y la confrontación con el gobierno, bajo el cálculo racional de evitar los costos y el desgaste que implicaría ser identificado como socio y soporte del gobierno en la arena legislativa.

Cheibub, Przeworski \& Saiegh (2004) y Cheibub (2007) — que observan el funcionamiento del presidencialismo desde la perspectiva del parlamentaris- 
mo- consideran que los gobiernos en minoría surgen cuando hay distancias moderadas en las preferencias políticas y operarían debido a las concesiones del gobierno en políticas ante los partidos de oposición para ganar apoyos puntuales. Solo que en el parlamentarismo, a diferencia de los sistemas presidenciales, cuando los costos de mantener el gobierno exceden los beneficios que obtienen los partidos de oposición, se adelantan las elecciones para renovarlo. En cambio, en los sistemas presidenciales, dado el periodo fijo de mandato, el gobierno continuaría operando con un Congreso poco dispuesto a colaborar.

Figueiredo, Vieira \& Canello (2012) han encontrado que la conformación de gobiernos en minoría en América Latina es considerable, ${ }^{2}$ y que su aparición en la región se debe a la debilidad de los poderes de agenda positivos del presidente, ${ }^{3}$ a una baja fraccionalización del sistema de partidos ${ }^{4}$ y a una distancia ideológica moderada. Las tres consideraciones se asocian a la lógica de mantenimiento y operación de los gobiernos parlamentarios en minoría. Strøm (1991), por su parte, ha identificado que los parlamentos europeos con mayores atribuciones para influir en las políticas — con un sistema de comisiones fuerte- potencian a los partidos de oposición en el Congreso y reducen los costos de no formar parte del gobierno. Además de estas características, siguiendo a este mismo autor, junto con la baja fraccionalización del sistema de partidos, serían los factores que incrementarían las probabilidades de surgimiento de gobiernos de minoría en sistemas parlamentarios. Ello porque estos partidos se benefician influenciando las políticas desde el parlamento, liberándose de los costos de formar parte de una coalición gubernamental, pero viabilizando su mantenimiento. Sería de esperar que los partidos de oposición en gobiernos en minoría bajo sistemas presidenciales multipartidistas también influyan en las políticas desde el Congreso, a manera de condición previa para otorgar su apoyo a la aprobación de las políticas gubernamentales.

Esta estrategia de colaboración con el gobierno por parte de las agrupaciones de oposición estaría acompasada por otra de priorización de votos. Una proximidad de las elecciones incrementa los riesgos de fuga de votos que conlleva el acercamiento y la colaboración con el gobierno para los partidos de oposición.

2 El estudio de Figueiredo, Vieira \& Canello (2012) va de 1979 a 2011, abarca 79 periodos presidenciales, la unidad de análisis es el ańo en gobierno y comprende 287 observaciones. Ellos encontraron que el $47.7 \%$ de estas corresponde a gobiernos en minoría que pueden ser ya sea de conformación unipartidista o de coalición multipartidista.

3 Shugart \& Carey (1992) ya intuían que los presidentes con débiles poderes legislativos tenderían a hacer poco problemático el presidencialismo, ya que necesariamente negociarían la aprobación de sus políticas con el Congreso - lo que fortalece a esta institución política y a sus actores - evitando el llamado "juego suma cero" identificado por Linz (1990) que induciría al conflicto entre las ramas de gobierno.

4 Según Sartori, un pluralismo moderado va de tres a cinco partidos. 
En general, conforme se acerca un periodo electoral las prioridades partidistas se concentran en una estrategia cuyas premisas son la maximización de votos y el minimizar los riesgos de que estos últimos se fuguen. Budge \& Laver (1986, p. 497) expresan gráficamente este cambio en las prioridades al afirmar que "el partido pelearía con uñas y dientes por las políticas simplemente para impresionar a los votantes más interesados en tales políticas". Bajo gobiernos en minoría en sistemas parlamentarios, este cambio de objetivos lleva al adelanto de elecciones. En sistemas presidenciales, sin embargo, dado el periodo fijo de mandato, tal cambio de prioridades conllevaría a que las fuerzas de oposición hostilicen con la esfera gubernamental.

\section{Contexto político y diseño institucional: el caso mexicano}

El caso mexicano del periodo 1997-2012 se caracteriza por un contexto de gobierno en minoría enfrentado a partidos de oposición fuertes y cohesionados en un régimen presidencial. A diferencia de otros sistemas de partidos de la región, el de México se conforma de tres partidos políticos institucionalizados - tanto en su dimensión ideológica, como en su permanencia en el tiempo, raigambre territorial y estabilidad electoral- y disciplinados, con porcentajes de apoyo electoral que producen una representación legislativa en el Congreso que no alcanza diferencias sustanciales entre sí (Casar, 2013; Fernandez-Albertos \& Lapuente, 2010; Nacif, 2002; Zechmeister, 2010). Ello hace que estos agentes partidistas sostengan serias aspiraciones de ganar las elecciones presidenciales. Bajo esta premisa electoral, la oposición forja una relación interactiva tanto de colaboración legislativa como de confrontación con el Ejecutivo. ${ }^{5}$ Pero, en todo caso, los erige en agentes indispensables a persuadir por el presidente para lograr la aprobación de sus proyectos de ley.

Previo a la transición política de 1997, el régimen de partido hegemónico permitió que los presidentes del Partido Revolucionario Institucional (PRI) dominaran la actividad legislativa, y anularan en la práctica la división de poderes y toda competencia real por parte de la oposición. El proceso de reformas electorales iniciado en 1977 amplió en forma progresiva los espacios ocupados por los partidos de oposición configurando así un sistema basado en tres partidos sin considerables diferencias entre sí respecto al número de escaños ocupados.

5 Los restantes partidos son de tamaño legislativo reducido, por lo que coaligarse con ellos no es suficiente para que los presidentes en minoría en México logren la aprobación de sus proyectos de ley. Además, el legislador mexicano actúa en el Congreso de manera disciplinada siguiendo generalmente las directrices de los dirigentes del partido al que pertenece (Béjar, 2003; Nacif, 2002). 
Todo esto se cristalizó en 1997 cuando por primera vez un presidente priista se encontró en la Cámara de Diputados en minoría enfrentando a dos fuertes partidos de oposición: uno de centroderecha, el Partido Acción Nacional (PAN), y otro de centroizquierda, el Partido de la Revolución Democrática (PRD). Desde dicho ańo hasta 2012 — cinco legislaturas — el partido del presidente en la Cámara de Diputados no rebasó el $47 \%$ y descendió incluso hasta el $28 \%$ de los espacios legislativos. En tanto que la suma de los escańos de los partidos de oposición osciló entre el 71 y 59\% y se concentró sobre todo en dos partidos altamente competitivos. ${ }^{6}$

Este importante peso de los partidos de oposición y sus probabilidades reales de ganar las elecciones presidenciales, hizo suponer que rivalizarían directamente con el Ejecutivo. ${ }^{7}$ Ello activaría un juego de vetos mutuos entre partidos que dificultaría el desahogo de la agenda legislativa. La tabla 1 demuestra que esto no ocurrió, ya que, además de que el Ejecutivo muestra una alta efectividad al lograr que la mayor parte de sus iniciativas sean aprobadas, los principales partidos de oposición también logran que sus iniciativas se aprueben. La tabla 1 destaca tres elementos: $i$ ) entre los partidos de oposición y el gubernamental se desencadenó una dinámica de intensas negociaciones e intercambios para defender y promover sus intereses; ii) los partidos no instrumentaron una estrategia de bloqueo sistemático al Ejecutivo, y iii) este actor implementó una estrategia de negociación continua con los partidos de oposición para atraerse el apoyo de por lo menos uno de ellos y lograr la aprobación de su agenda. Esta distribución colocó a los agentes de oposición en un lugar estratégico para influir en el contenido de la agenda legislativa a cambio de otorgar su apoyo en el Congreso.

Las comisiones, y el sistema que componen en la Cámara de Diputados, son el espacio donde las iniciativas se analizan, enmiendan, bloquean o se abren paso, para su votación final. Es la arena donde las agrupaciones de oposición ejercen su influencia — por medio de la enmienda — sobre las iniciativas del Ejecutivo en el Congreso, aunque también pueden presentarse y aprobarse enmiendas en el Pleno. Pero la centralidad de las comisiones en el proceso de enmiendas se debe al marco institucional que regula el procedimiento legislativo formal del Congreso

6 El PAN y el PRD fueron los principales partidos de oposición en la Legislatura LVII (1997-2000), y en las subsiguientes cuatro, el PRI y el PRD. La concentración de espacios legislativos entre estos dos osciló entre el 49.2 y el $63.4 \%$ de los escańos.

7 El Ejecutivo mexicano es uno de los más débiles de América Latina en cuanto a atribuciones legislativas se refiere para presionar al Congreso (Haggard \& Shugart, 2001; Payne \& Zovatto, 2003; PNUD, 2004; Samuels \& Shugart, 2003; Scartascini, Spiller, Stein \& Tommasi, 2010; Shugart \& Carey, 1992). Dicha escasez hace que los presidentes mexicanos deban negociar con los partidos de oposición la aprobación de su agenda legislativa en el Congreso. 
en México. Todas las iniciativas presentadas en la Cámara deben ser turnadas de inmediato a una comisión o a múltiples comisiones, según sea el caso, para que con base en su análisis y discusión se emita un dictamen. ${ }^{8}$ En estos reportes se hace constar si las iniciativas en cuestión son rechazadas por la comisión, si son aprobadas y si son plasmadas las modificaciones llevadas a cabo. Estos reportes deben aprobarse por la mayoría de los miembros de la comisión.?

Tabla 1. Iniciativas legislativas del Poder Ejecutivo-partido en el gobierno y partidos de oposición con mayor representación en la Cámara de Diputados, 1997-2012

\begin{tabular}{|c|c|c|c|c|c|c|c|c|c|c|}
\hline & \multicolumn{4}{|c|}{ Presentadas } & \multicolumn{4}{|c|}{ Aprobadas } & \multicolumn{2}{|c|}{ Total de iniciativas } \\
\hline & \multicolumn{2}{|c|}{ Gobierno } & \multicolumn{2}{|c|}{ Oposición } & \multicolumn{2}{|c|}{ Gobierno } & \multicolumn{2}{|c|}{ Oposición } & \multirow[b]{2}{*}{ Presentadas } & \multirow[b]{2}{*}{ Aprobadas } \\
\hline & $\begin{array}{c}\text { Poder } \\
\text { Eje. }\end{array}$ & $\begin{array}{l}\text { Pdo. pol. } \\
\text { en gob. }\end{array}$ & $\begin{array}{l}\text { PRI O } \\
\text { PAN }\end{array}$ & $P R D$ & $\begin{array}{c}\text { Poder } \\
\text { Eje. }\end{array}$ & $\begin{array}{l}\text { Pdo. pol. } \\
\text { en gob. }\end{array}$ & $\begin{array}{l}\text { PRIO } \\
\text { PAN }\end{array}$ & $P R D$ & & \\
\hline $\begin{array}{l}\text { Legislatura } \\
\text { 1997-2000* }\end{array}$ & 36 & 79 & 157 & 158 & 32 & 16 & 30 & 27 & 430 & 105 \\
\hline $\begin{array}{l}\text { Legislatura } \\
2000-2003^{\star \star}\end{array}$ & 63 & 245 & 261 & 273 & 55 & 58 & 57 & 54 & 842 & 224 \\
\hline $\begin{array}{l}\text { Legislatura } \\
2003-2006^{\star \star}\end{array}$ & 49 & 559 & 966 & 487 & 31 & 79 & 145 & 53 & 2,061 & 308 \\
\hline $\begin{array}{l}\text { Legislatura } \\
2006-2009^{\star \star}\end{array}$ & 42 & 611 & 695 & 682 & 38 & 99 & 91 & 68 & 2,030 & 296 \\
\hline $\begin{array}{l}\text { Legislatura } \\
2009-2012^{\star \star}\end{array}$ & 32 & 780 & 1308 & 507 & 25 & 47 & 68 & 21 & 2,627 & 161 \\
\hline
\end{tabular}

Partidos en el gobierno: *PRI, ${ }^{\star *}$ PAN.

Fuente: Elaboración propia con datos del Sistema de Información Legislativa (SIL) (2012).

Las comisiones de la Cámara de Diputados mexicana no tienen restricción alguna para efectuar enmiendas, ni en la profundidad ni en la cantidad de los cambios efectuados. Las discusiones finales en el Pleno del Congreso tienen como objeto el dictamen, que luego es votado por el total de la Cámara; y la legislación aplicada es la referida en el informe de comisiones aprobado por el Congreso. Por esta razón, Nacif (2000) sostiene que la esfera de autoridad de la comisiones en México es extensa.

8 Esto es así salvo que las iniciativas se tramiten con urgencia por resolución del Pleno, para lo cual se requieren de las dos terceras partes de los presentes (arts. 59 y 60 del Reglamento para el Gobierno Interior de Congreso General de los Estados Unidos Mexicanos — RGICGeuM, en adelante-, y arts. 65, 113 del Reglamento de la Cámara de Diputados (RCD, en adelante). Por otra parte, es atribución del presidente de la Mesa Directiva de la Cámara de Diputados la designación de la comisión o comisiones para el análisis y dictamen de las iniciativas (art. 66, RCD).

9 Otra función clave de las comisiones es la de controlar la producción legislativa, ya que podrían negarse a efectuar algún análisis y optar por bloquear algún proyecto de ley (Shepsle \& Weingast, 1981). Sin embargo, esta línea de análisis no se aborda aquí. 
Pero si bien hay consenso sobre el rol otorgado formalmente a las comisiones en los procesos legislativos, estas interactúan en un sistema que rebasa su esfera de autoridad y que afecta su funcionamiento. Un factor que influye en el tipo de funcionamiento de las comisiones es la prohibición constitucional de la reelección consecutiva a los puestos de elección, como es el de legislador. Aunque recientemente esta prohibición se levantó, estuvo vigente entre 1933 y 2014 . Algunos de sus efectos fueron que los legisladores buscaran un puesto político fuera del Congreso al finalizar su periodo; que los legisladores actuaran disciplinadamente en el Congreso ante sus liderazgos partidistas puesto que estos bloquean o impulsan sus carreras políticas, ${ }^{10} \mathrm{y}$ que el accionar legislativo de las comisiones se viera limitado por los acuerdos intrapartidistas. ${ }^{11}$

\section{Variable dependiente: la influencia de la oposición}

El análisis de este artículo está enfocado en las enmiendas a las iniciativas de los presidentes de México que las agrupaciones de oposición han impulsado en la etapa de aprobación y trámite en la Cámara de Diputados, en contextos de gobiernos de minoría, es decir, en circunstancias en las que el Poder Ejecutivo requiere del apoyo de alguno de los principales grupos de oposición para obtener la aprobación de sus proyectos de ley. Entonces, aunque aquí se analiza a los grupos legislativos con poder de veto en la toma de decisiones, el objetivo específico es observar la influencia — a través de las enmiendas- que ellos ejercen en este tipo de colaboración. Con ese fin se ha hecho una delimitación: se han excluido del análisis $i$ ) las iniciativas del Ejecutivo no aprobadas en el Congreso, ya que en estos casos la oposición con poder de veto no colabora; ii) las iniciativas que no fueron modificadas en el trámite legislativo, pues esto indicaría que no hubo influencia visible formal alguna en sus respectivos trámites legislativos; iii) las iniciativas relativas a los proyectos de ingresos y egresos presupuestales, ya que su tramitación es un espacio natural de influencia de la oposición legislativa, y apartarlas del análisis brinda una aproximación más

10 De 1946 a 2012, cuando se reforma la Constitución para introducir la figura de los candidatos que pueden postularse a elecciones sin necesidad de los partidos políticos, estos habían monopolizado la postulación de los candidatos a cargos de elección. Este hecho, junto con la prohibición de la reelección, ha fortalecido el control de las dirigencias partidistas sobre sus cuadros.

11 La pluralidad política en México desde 1997 ha propiciado que tomen un rol cada vez más destacado los gobernadores de los estados del país, las asociaciones sindicales y otros grupos de interés, que cuentan con poderosos instrumentos para distribuir recursos y promover las carreras políticas de los legisladores. 
real de la influencia de la oposición en planos no predeterminados para que estos grupos la ejerzan.

Por otra parte, cabe acotar que los procesos legislativos relativos a la aprobación de los presupuestos de ingresos y egresos también están sujetos a una regulación distinta que los proyectos de ley ordinarios, lo que implicaría su análisis específico.

El conjunto de proyectos de ley del Ejecutivo resultante de la aplicación de los criterios mencionado constituirá el corpus para determinar el peso de la influencia legislativa de los partidos de oposición en el contenido de la agenda legislativa presidencial.

Después de lo anterior se analizará el recorrido legislativo de las iniciativas de ley emanadas del Ejecutivo que cumplieron con los criterios descritos. La información recogida del trámite legislativo en la Cámara de Diputados proviene de dos etapas: 1) del análisis en comisiones y las enmiendas ahí efectuadas, y 2) de la discusión del dictamen en el Pleno presentado por las comisiones con las enmiendas cuando estas se dieron. Las modificaciones se han contabilizado y examinado para cada iniciativa, registrando la afiliación partidista de su autor o autores para identificar a los legisladores pertenecientes a la oposición. Se registró como enmienda toda la que fue aprobada y propuesta por un legislador de la oposición o que tuvo como coautor a uno de estos.

El nivel de detalle de la información disponible respecto al análisis llevado a cabo en las comisiones varía según los países. En esta investigación se sigue a Bonvecchi \& Zelaznik (2010) para cuando no es posible identificar al autor de la enmienda. Estos autores revisaron los reportes o dictámenes de las comisiones para el caso argentino, donde quedan asentadas las modificaciones, así como las firmas de los legisladores que estuvieron de acuerdo o en desacuerdo con el dictamen. Y asumen como proponentes de las modificaciones a los legisladores firmantes del dictamen emitido por la comisión, y que fue posteriormente discutido en el Pleno de la Cámara. ${ }^{12}$

12 De la información disponible acerca del trámite legislativo a nivel de comisiones solo es posible extraer la cantidad y el contenido de cada enmienda aprobada, y los legisladores que la apoyaron con su firma, lo que impide conocer los nombres de los autores, así como las enmiendas no aprobadas. No obstante, la información identifica al partido de oposición que apoyó en comisiones las enmiendas, y al que no las apoyó. Cabe una observación adicional. Dada la condición de gobierno de minoría, al partido gubernamental en el Congreso le era imprescindible el apoyo de los legisladores de cuando menos uno de los principales partidos de la oposición para que el proyecto del presidente superara la etapa de comisiones. Así, los dictámenes aprobados tendrán el apoyo de los legisladores del partido en el gobierno y cuando menos el de un partido de oposición. Para Bonvecchi \& Zelaznik (2010) esta combinación de firmas gobierno-oposición refleja un ambiente de colaboración y consenso en comisiones entre estas fuerzas políticas rivales. En efecto, pero en el caso mexicano una circunstancia así favorece a la oposición.

C. Vázquez Ferrel | La influencia legislativa de la oposición en las iniciativas de los gobiernos en minoría en México, 1997-2012 | Perfiles Latinoamericanos, 27(54) | FLACso México | DoI: 10.18504/pl2754-006-2019 
La influencia legislativa de la oposición se ha captado mediante el análisis del cambio que implica cada enmienda. Para ello, las enmiendas efectuadas con el apoyo de los grupos de oposición se clasifican con la tipología de Barrett $\&$ Eshbaugh-Soha (2007) con algunos ajustes (véase el anexo 1), y después se les reclasifica según la magnitud de cambio que denota su contenido con base en las categorías neutrales de contención y proactivas. Estas últimas se utilizan como indicadores.

La tabla 2 muestra los proyectos de ley que cumplieron los criterios ya descritos, así como las cantidades de enmiendas efectuadas que la oposición impulsó y los porcentajes relacionados con la clasificación. ${ }^{13}$ En dicha tabla 2 sobresale que i) a lo largo de este periodo se registró una amplia cantidad de enmiendas: las más altas cifras se produjeron en las legislaturas LVIII (20002003) y LX (2006-2009), que coinciden con los inicios de los mandatos de los presidentes Vicente Fox (2000-2006) y Felipe Calderón (2009-2012); ii) que a pesar de esta alta cantidad, en la legislatura inicial del sexenio de Vicente Fox se emite una baja proporción de enmiendas proactivas, en comparación con la legislatura inicial de Felipe Calderón, etapa que, no obstante el descenso en la cantidad de enmiendas, revela la mayor proporción de enmiendas proactivas en el periodo de estudio, y iii) que en los periodos legislativos coincidentes con el fin de los mandatos y que, por ello, próximos a la convocatoria de renovación del Ejecutivo - LIX (2003-2006), LXI (2009-2012) y LVII (1997-2000)_ desciende la cantidad de enmiendas efectuadas y se incrementa sustancialmente la proporción de las de contención.

Tabla 2. Proyectos de ley: cantidad y clasificación de enmiendas en la Cámara de Diputados

\begin{tabular}{|c|c|c|c|c|c|c|c|}
\hline \multirow[b]{2}{*}{ Presidentes } & \multirow[b]{2}{*}{ Legislatura } & \multirow[b]{2}{*}{$\begin{array}{c}\text { Cantidad de } \\
\text { iniciativas }\end{array}$} & \multicolumn{5}{|c|}{ Enmiendas } \\
\hline & & & $\begin{array}{l}\text { Enmiendas } \\
\text { efectuadas }\end{array}$ & $\begin{array}{l}\text { Promedio de } \\
\text { enmiendas }\end{array}$ & $\begin{array}{l}\text { Neutrales } \\
(\%)\end{array}$ & $\begin{array}{c}\text { Contención } \\
(\%)\end{array}$ & $\begin{array}{c}\text { Proactivas } \\
\text { (\%) }\end{array}$ \\
\hline $\begin{array}{l}\text { Ernesto Zedillo } \\
\text { (PRI) }\end{array}$ & LVII & 16 & 324 & 20.25 & 29.01 & 43.52 & 27.47 \\
\hline \multirow{2}{*}{$\begin{array}{l}\text { Vicente Fox } \\
\text { (PAN) }\end{array}$} & LVIII & 34 & 781 & 22.97 & 32.26 & 38.54 & 29.19 \\
\hline & LIX & 22 & 177 & 8.04 & 23.16 & 46.33 & 30.51 \\
\hline \multirow{3}{*}{$\begin{array}{l}\text { Felipe Calderón } \\
\text { (PAN) }\end{array}$} & $L X$ & 22 & 256 & 11.63 & 23.44 & 33.20 & 43.36 \\
\hline & LXI & 12 & 109 & 9.08 & 35.78 & 51.38 & 12.84 \\
\hline & Total & 106 & 1,647 & 15.53 & & & \\
\hline
\end{tabular}

Fuente: Elaboración propia con datos del Sistema de Información Legislativa de México (SIL) (2012) y la página web de la Cámara de Diputados, México (2012).

13 En el periodo de estudio, el Ejecutivo envió a la Cámara de Diputados 222 proyectos de ley. De estos, 39 no fueron aprobados, 29 fueron proyectos de ingresos o egresos, y 43 no recibieron enmienda alguna. 
Puesto que el objetivo de este trabajo es aportar un marco analítico-explicativo tentativo para aproximarnos a la influencia de la oposición, en esta sección se delinean los argumentos e hipótesis a contrastar. Los factores que inciden positivamente en la influencia legislativa de la oposición se han organizado en dos modelos con información relativa a las variables vinculadas al sistema partidista y a los factores político-contextuales. Las primeras son relevantes porque muestran la cantidad de agentes involucrados en los procesos de negociaciones, el peso del bloque de la oposición en su relación con el gobierno y la proximidad ideológica entre los agentes. Por su parte, el contexto donde actúan las variables partidistas es dinámico y ello inhibe o propicia la influencia legislativa de la oposición. Como variables para capturar los cambios políticocontextuales, se analizan el tipo de comisión, el ciclo electoral, la etapa de la "luna de miel", y la popularidad del presidente.

Dado que se busca explicar los cambios en la influencia de la oposición en contextos donde el presidente necesita del apoyo de algún grupo de oposición para aprobar sus iniciativas, la composición de las comisiones juega un rol clave en la enmienda. Al respecto, Toro \& Hurtado (2010), acerca del Congreso chileno, señalan que los legisladores gubernamentales fueron capaces de proteger en la comisión las iniciativas presidenciales de las enmiendas opositoras. Aprovechando tales conclusiones para este artículo, es posible decir que una menor proporción de legisladores del partido o coalición en el gobierno en las comisiones resultaría en una mayor presencia de los grupos de oposición, cuyas enmiendas tendrían más probabilidades de aprobación. La hipótesis sería la siguiente:

H1.1: A mayor proporción de legisladores de la oposición en comisiones, más probabilidad de que su influencia se incremente a través de las enmiendas efectuadas. ${ }^{14}$

Por otra parte, orientando el análisis hacia los efectos de la composición del Congreso, diversos trabajos han insistido en que la relación entre el Ejecutivo y el Legislativo está pautada por la cantidad de partidos (Chasquetti, 2008; Mainwaring \& Shugart, 2002a; Sani \& Sartori, 1980). Un alto número de partidos fragmenta el poder, lo que hace más probable que la base parti-

14 Para capturar los cambios en la proporción de legisladores de oposición en las comisiones, se ha recurrido a la composición partidista de la comisión que se registra en los reportes (dictámenes). Esta información permite identificar esos cambios por cada trámite legislativo. 
dista del presidente se reduzca en el Congreso y que conforme aumenten los partidos disminuya el control del presidente. Esto a su vez dispersaría la participación legislativa hacia otros agentes partidistas y extendería la influencia legislativa de la oposición.

Sin embargo, Cheibub, Przeworski \& Saiegh (2004), en su análisis sobre el éxito legislativo, encontraron que la construcción de coaliciones se dificulta no por un alto número de partidos, sino más bien cuando hay unos pocos partidos con fuerza similar, lo cual los lleva a rivalizar entre sí y a que disminuya su colaboración. Así, la influencia de la oposición en los proyectos de ley impulsados por el Ejecutivo también se reduciría. Las hipótesis respecto del número de partidos son las siguientes: ${ }^{15}$

H1.2.1: A mayor número de partidos con representación en el Congreso, más probabilidades de que se incremente la influencia legislativa —a la luz de las enmiendas efectuadas - de las agrupaciones de oposición.

Pero,

H.1.2.2: Cuanto más similar sea la fuerza legislativa del número de partidos, mayor probabilidad de que no llegue a incrementarse la influencia de la oposición.

Sin embargo, no hay una relación lo suficientemente clara entre el número de partidos y la fortaleza de la oposición. Así como un alto número de partidos puede dispersar la influencia partidista del gobierno en el Congreso, también podría afectar la cohesión del bloque de partidos en la oposición — entendida esta como la cantidad de partidos que la componen - , lo que afectaría su capacidad para actuar de manera estratégica. Además, un alto número de partidos incrementa las probabilidades de que el Ejecutivo se coaligue informalmente con alguno de los partidos de la oposición, inhiba su acción opositora, y logre así la aprobación de piezas legislativas concretas.

Para solventar la dificultad del multipartidismo en la oposición, se ha utilizado el índice de oposición efectiva (IOE) elaborado por Altman \& Pérez-Liñán (1999). ${ }^{16}$ El IOE adquiere valores de 0 cuando, por ejemplo, el

15 El indicador utilizado para calcular la cantidad de partidos es el número efectivo de partidos (NEP) de Laakso \& Taagepera (1979), quienes utilizan la fórmula NEP $=1 / \sum_{i=1}^{n} p i^{2}$ donde $p i$ es la proporción de escaños ocupados por el partido $\mathrm{N}$.

16 Al penalizar la fragmentación del bloque de partidos de oposición en favor del partido opositor con más amplitud legislativa, este indicador reflejaría con nitidez el tamańo de los partidos integrantes de 
gobierno controla todos los escańos del Congreso; toma el valor de 1 cuando el partido típico de la oposición controla la misma cantidad de escańos que el partido o coalición de partidos en el gobierno, y adquiere valores superiores a 1 cuando la oposición es más poderosa en el Congreso que la representación partidista gubernamental. Valores más allá de 1 implicarían, por lo tanto, una fuerza sustancial de la oposición para controlar al gobierno, hasta el punto de que inhibiría la actuación legislativa del Ejecutivo en el Congreso para evitar los riesgos de que sus proyectos sean derrotados en esta Cámara. Por esto, una oposición excesivamente fuerte disminuye los ritmos legislativos desencadenados por los proyectos de ley del Ejecutivo y, en consecuencia, debilita la influencia opositora. Las hipótesis respecto a la composición de la oposición (IOE) son las siguientes:

H1.3.1: A mayor fortaleza de la oposición (mayor IOE), más probabilidad de que los partidos de oposición incrementen su influencia legislativa sobre los proyectos del Ejecutivo.

Pero,

H.1.3.2: A valores IOE por encima de 1 —esto es, a oposiciones excesivamente fuertes - más probabilidades de inhibir el rol legislativo del Ejecutivo, y de que ello eleve las probabilidades de que disminuya la influencia de la oposición —a través de las enmiendas efectuadas- en los proyectos del Ejecutivo.

Por otra parte, en contextos de gobierno en minoría, las coaliciones se vuelven indispensables. En el análisis de la formación de coaliciones la proximidad ideológica ha sido un factor explicativo importante abordado por la literatura. Las diversas combinaciones de coaliciones entre los actores políticos están reguladas por la cantidad de actores con poder de veto, su cohesión y la distancia ideológica entre ellos (Axelrod, 1986; Colomer \& Negretto, 2003, 2005; Laver \& Shepsle, 2012; Tsebelis, 2006; Alemán \& Tsebelis, 2011). En este artículo el factor ideológico sirve como elemento predictivo para que los agentes se coaliguen, y en particular se analiza la proximidad entre actores a la luz el continuum

la oposición, la cohesión de la oposición como bloque, y brindaría una idea clara de sus probabilidades para influir en la actividad legislativa. La fórmula utilizada es

IEO $=\frac{O}{G}$, donde $O=\frac{\Sigma o_{i}^{2}}{\Sigma o_{i}}$, así como $G=\frac{\Sigma g_{i}^{2}}{\Sigma g_{i}}$ 
ideológico izquierda-derecha. ${ }^{17}$ La hipótesis acerca de la proximidad ideológica entre el presidente y los partidos de oposición es la siguiente:

H.1.4.1: A mayor proximidad ideológica entre el partido de oposición y el partido del presidente, más probabilidad de que se coaliguen y el partido de oposición ejerza mayor influencia legislativa.

La tabla 3 muestra las estadísticas descriptivas de las variables relativas a la dinámica del sistema de partidos para las cinco legislaturas englobadas en el periodo de estudio. Adelante, la tabla 4 muestra los cambios en la proporción de legisladores de oposición del bloque de legisladores opositor para cada comisión perteneciente a la Cámara de Diputados que participó en las discusiones y examen de los proyectos de ley presentados por el Ejecutivo y que se analizan en este texto. Los datos fueron recabados de los dictámenes elaborados por las comisiones, en los que son identificados los legisladores pertenecientes al bloque de la oposición. Además, en la parte superior (en cursiva) aparece el porcentaje del bloque de legisladores de oposición en la Cámara de Diputados. La ausencia de alguna leyenda en las celdas de la tabla alude a la no participación por parte de estas comisiones en la discusión de las iniciativas provenientes del Ejecutivo para esas legislaturas. Adicionalmente, la distribución de las comisiones mostradas en la tabla 4 se ha ordenado en función del peso que tuvieron en la proporción de enmiendas emitidas, un aspecto estrechamente vinculado a una de las variables pertenecientes al modelo denominado político-contextual.

Tabla 3. Descriptivos de variables relativas a la dinámica del sistema de partidos

\begin{tabular}{llccc}
\hline Legislatura & NEP & IOE & $\begin{array}{c}\text { Próx. ideo. PRD-Pdo. } \\
\text { pol. en gob. }\end{array}$ & Próx. Ideo. PRI-PAN. \\
\hline LVII & 2.85 & 0.48 & .720 & 0.93 \\
LVIII & 2.80 & 0.76 & 0.68 & 0.87 \\
LIX & 3.06 & 1.11 & 0.59 & 0.86 \\
LX & 3.55 & 0.45 & 0.56 & 0.80 \\
LXI & 2.99 & 1.24 & 0.67 & 0.83 \\
\hline
\end{tabular}

Fuente: Elaboración propia

17 La proximidad ideológica se ha estimado con la información recogida en las encuestas aplicadas a los legisladores en las que estos se sitúan en el continuum ideológico izquierda-derecha, mismo ámbito en el que ubican al partido del presidente. La información proviene del proyecto "Observatorio de élites parlamentarias en América Latina”, de la Universidad de Salamanca, Espańa. La fórmula para estimar la proximidad ideológica es la de Sani \& Sartori (1980) ajustada por García \& Martínez (2002): $1-\left\lceil\frac{x_{1}-x_{g p}}{9}\right\rceil$. 


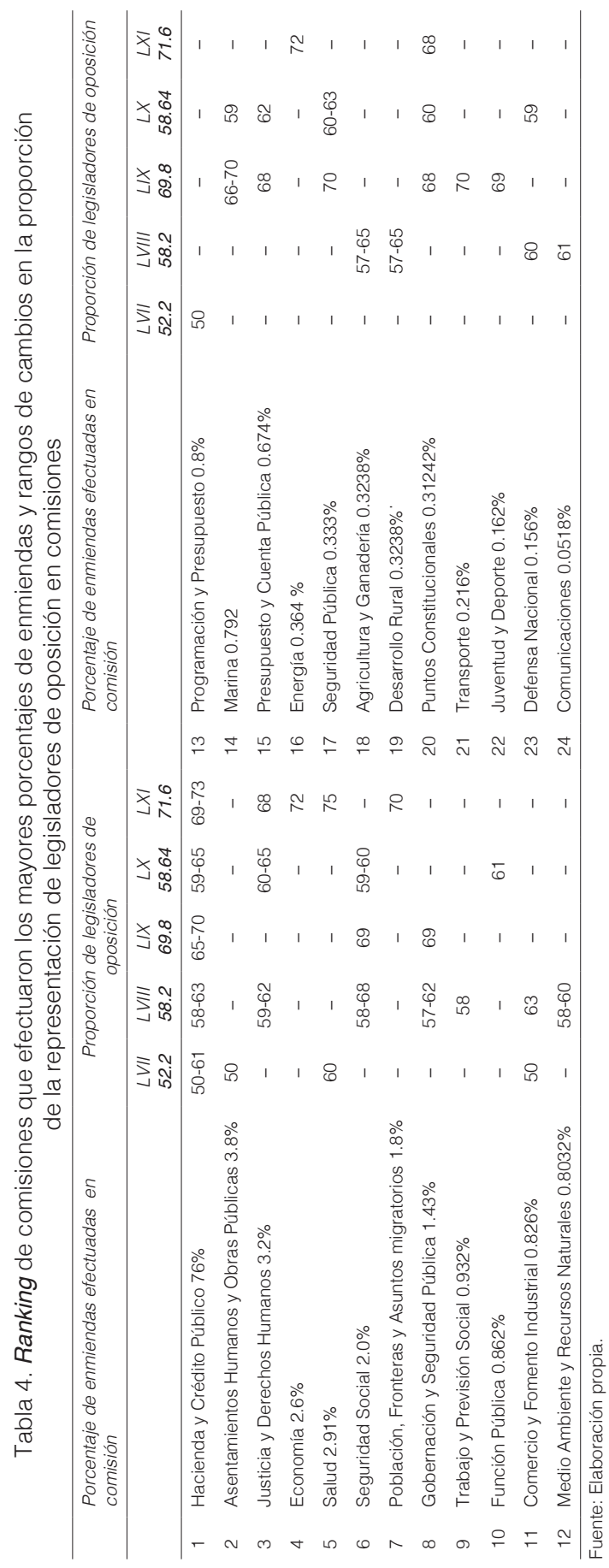

C. Vázquez Ferrel | La influencia legislativa de la oposición en las iniciativas de los gobiernos en minoría en México, 1997-2012 | Perfiles Latinoamericanos, 27(54) | FLACso México | DoI: 10.18504/pl2754-006-2019 
Las variables relativas el modelo político-contextual marcarían los ritmos de la influencia de la oposición. La primera de ellas es la delegación que los liderazgos partidistas depositen en sus legisladores para comisiones específicas. Esos liderazgos muchas veces se apropian de procesos concretos, lo que disminuye la participación del Congreso y de las comisiones. Ello sería más evidente para los casos de países con partidos políticos institucionalizados y con capacidad de actuación disciplinada en el Congreso, como lo es México (Nacif, 2002). Una mayor delegación por parte de los partidos en el Congreso genera el escenario apropiado para que en las comisiones se intensifique su accionar legislativo, como sucede en las comisiones ubicadas en la parte superior del ranking mostrado en la tabla 4. Con frecuencia, algunas de las comisiones que suelen contar con mayor margen de acción legislativo son la de Hacienda y Crédito Público y la de Gobernación, entre otras. Mientras que un menor margen de actuación y de delegación en las comisiones disminuiría su accionar legislativo, entendido este como las enmiendas impulsadas por la oposición.

Para distinguir el perfil de las comisiones se ha recurrido a la propuesta de Masters (1961) ajustándola para esta investigación. Esta clasificación permite distinguir a las comisiones que reciben la mayor cantidad de iniciativas (las Mayores, vinculadas al sector fiscal y al de derechos, justicia y gobernación), y se les delega más funciones legislativas, de las que reciben iniciativas vinculadas a temas sectoriales concretos (las issue) y que podrían desarrollar una participación legislativa más puntual. ${ }^{18}$ En este caso la hipótesis sería la siguiente:

H.2.1.1: Cuanta mayor delegación, más probabilidades de que se incremente la influencia de la oposición.

Por otra parte, el ciclo electoral y la "luna de miel" son variables incluidas también en el modelo político-contextual. La "luna de miel" estaría marcada por el inicio del mandato presidencial y la combinación de elementos como el tiempo inmediato posterior al estreno del presidente al frente del gobierno y una disposición positiva por parte de diversos actores para negociar con él, y

18 Las comisiones issue son: Asentamientos Humanos y Obras Públicas, Economía, Salud, Seguridad Social, Población Fronteras y Asuntos Migratorios, Trabajo y Previsión Social, Comercio y Fomento Industrial, Medio Ambiente y Recursos Naturales, Energía, Agricultura y Ganadería, Desarrollo Rural, Juventud y Deporte, y Comunicaciones. Las comisiones mayores vinculadas al sector fiscal son Hacienda y Crédito Público, Programación y Presupuesto, y Presupuesto y Cuenta Pública. Las comisiones mayores vinculadas al sector derecho, justicia y seguridad son Justicia y Derechos Humanos, Gobernación y Seguridad Pública, Seguridad Pública, Defensa Nacional, Marina, y Función Pública. 
una opinión pública y prensa que le es más o menos favorable. Estos elementos dan lugar a una relación productiva entre los actores políticos que se refleja en su mayor colaboración (Dominguez, 2001; Neustadt, 1960).

Sin embargo, conforme avanza el periodo de gobierno, los presidentes comúnmente se enfrentan a lo que Light (1999) denomina ciclo de descenso de influencia del presidente para atraerse las diferentes fuerzas, negociar y lograr la aprobación de sus políticas. Este ciclo se gesta por la progresiva erosión del apoyo público que recibe el Ejecutivo, una probable disminución de los espacios legislativos del partido en el gobierno o coalición en las elecciones intermedias, y por un clima dominado por los fracasos presidenciales. Ante este desgaste, los legisladores se comportan distanciándose progresivamente del presidente para evitar ser identificados como sus cercanos y proteger su futuro electoral (Mejía \& Polga-Hecimovich, 2011). Asimismo, una vez que el periodo electoral se encuentre más próximo, las fuerzas políticas acrecentarán su distanciamiento del gobierno subrayando sus diferencias entre sí enarbolando una oferta política distinta a la gubernamental, en una estrategia centrada en el vote-seeking, para atraer una mayor cantidad de votos. ${ }^{19}$ Las hipótesis al respecto serían:

H.2.2.1: A mayor distancia de las próximas elecciones, más probabilidad de que los grupos de oposición incrementen su influencia legislativa.

H.2.2.2: A mayor proximidad de las elecciones, más probabilidades de que disminuya la influencia de la oposición.

Una variable adicional contextual que se debe explorar son los niveles del apoyo popular para el presidente. Además de las atribuciones institucionales y partidistas, el jefe del Ejecutivo puede optar por fortalecer su liderazgo buscando el apoyo público para su agenda legislativa. Una mayor popularidad del presidente le permitiría incrementar su influencia impulsando temas específicos en la arena legislativa para persuadir a los liderazgos del Congreso de entablar negociaciones (Edwards III \& Barrett, 1999).

19 En esta investigación se considera que la "luna de miel" del presidente abarca los primeros dos años y el ańo y medio inmediato posterior a las elecciones de renovación del Congreso, es un momento de máxima lejanía de las elecciones, y por lo tanto se incrementan las probabilidades de que las agrupaciones de oposición colaboren con el gobierno de tal manera que aumentan su influencia en el diseńo de las políticas. Por su parte, el ciclo electoral en esta investigación es el ańo electoral para la renovación de la Cámara de Diputados, y el año electoral para la renovación del Ejecutivo, más los cinco meses previos a dicho año.

C. Vázquez Ferrel | La influencia legislativa de la oposición en las iniciativas de los gobiernos en minoría en México, 1997-2012 | Perfiles Latinoamericanos, 27(54) | FLACso México | DoI: 10.18504/pl2754-006-2019 
Una baja popularidad del presidente, sin embargo, alejaría a los grupos legislativos de las políticas que él promueve. Calvo (2007) analiza el Congreso argentino como caso de un parlamento "cartelizado" por partidos disciplinados, y ha hallado evidencia suficiente para respaldar la hipótesis de que este tipo de funcionamiento de "cárteles legislativos" es sensible a los cambios en la opinión pública, lo que impide que llegue al Pleno legislación potencialmente impopular que pueda generarle costos. Acompañar al jefe del Ejecutivo durante una baja popularidad o en temas muy impopulares, implicaría para los grupos legislativos, incluidos los de oposición, asumir riesgos de pérdida de votos (Alemán \& Calvo, 2007).

Por otra parte, cuando el presidente cuenta con alta popularidad y recibe más apoyo público para sus políticas impulsadas, el costo electoral para el Congreso se eleva si no responde al programa presidencial, por lo que hay más probabilidad de que los grupos legislativos muestren más disposición a negociarlo. Sin embargo, también es de esperar que la oposición busque desplegar estrategias legislativas paralelas que afecten ese apoyo público. Anticipando este escenario y el alto riesgo de que sus proyectos no se aprueben, el presidente disminuiría su presentación de iniciativas, lo que haría descender el ritmo legislativo con las repercusiones negativas en la influencia de la oposición. ${ }^{20}$ Para ello tenemos las siguientes hipótesis:

H.2.3.1: A mayor popularidad del presidente, más probabilidad de que los grupos de oposición ejerzan una mayor influencia legislativa.

Pero,

H.2.3.2: A mayor popularidad del presidente, más probabilidad de que los partidos de oposición instrumenten estrategias legislativas para afectar negativamente la popularidad de aquel y esto, por consecuencia, disminuya su rol legislativo y eleve las probabilidades de que se reduzcan las enmiendas efectuadas.

20 Las fuentes de información para recabar los niveles de aprobación de Vicente Fox (2000-2006) son los boletines trimestrales de Consulta Mitofsky, dirigida por Roy Campos, y El Juicio Ciudadano. Evaluación de la Presidencia de Felipe Calderón en México 2006-2012, de Campos (2012), para el caso de Felipe Calderón (2006-2012). Ambos recursos fueron facilitados por dicha empresa para este trabajo y siguen una misma metodología. Para el periodo del presidente Ernesto Zedillo (1997-2000), el recurso fue una colección de encuestas proveniente del Acervo de Opinión Pública de la Oficina de la Presidencia de la República Mexicana donado al Banco de Información para la Investigación Aplicada en Ciencias Sociales (BIIACs) del Centro de Investigación y Docencia Económicas (CIDE). 


\section{Resultados}

Las tablas 5 y 6 resumen los resultados de contrastar las hipótesis. Se reitera que la pretensión en este artículo es identificar los factores que incrementan la probabilidad de que se efectúe un tipo de enmienda, neutral, de contención o proactiva. Por las características de la variable dependiente se ha usado la técnica de regresión logística multinomial. Como se observa en las tablas 5 y 6 , los incrementos en el IOE en la Cámara de Diputados están asociados a la emisión de enmiendas de contención y disminuyen las probabilidades de que se emitan las proactivas. Durante el periodo en estudio, las tasas IOE superaron el valor de 1 en las legislaturas LIX y LXI, cuando la oposición fue sustancialmente fuerte y se inclinó por emitir enmiendas de contención. Esta relación coincide con la hipótesis de que en contextos con valores IOE por encima de 1 las fuerzas de oposición cuentan con una fuerza sustancial para controlar al Ejecutivo, el cual inhibe el rol de este en el Congreso y ello disminuye los ritmos legislativos desencadenados por la promoción de su agenda.

Tabla 5. Modelo de variables relativas al sistema de partidos

\begin{tabular}{|c|c|c|c|c|c|c|}
\hline \multirow[b]{2}{*}{ Variables } & \multicolumn{3}{|c|}{ Contención } & \multicolumn{3}{|c|}{ Proactivas } \\
\hline & $B$ & $\begin{array}{l}\text { Error } \\
\text { típ. }\end{array}$ & Exp. & $B$ & Error típ. & Exp \\
\hline IOE & $.590^{\star}$ & .348 & 1.819 & $-1.279^{\star \star}$ & .461 & .278 \\
\hline NEP & .693 & .735 & .289 & $-1.735^{\star}$ & .934 & .176 \\
\hline Proximidad ideológica PRI y PAN & $8.179^{\star \star}$ & 3.485 & .000 & $8.758^{\star *}$ & 3.696 & .000 \\
\hline $\begin{array}{l}\text { Proximidad ideológica PRD y partido en el } \\
\text { gobierno }\end{array}$ & -2.625 & 3.573 & 17.396 & $-16.581^{\star \star \star}$ & 4.537 & 17074252.8 \\
\hline $\begin{array}{l}\text { Proporción de legisladores de oposición en } \\
\text { comisiones }\end{array}$ & .001 & .004 & 1.002 & $.016^{\star \star}$ & .005 & 1.017 \\
\hline Nagelkerke .040 & & & & & & \\
\hline
\end{tabular}

En ambos modelos, el número efectivo de partidos (NEP) presenta una relación positiva con las enmiendas de contención, lo que se relaciona con los altos valores del NEP en las legislaturas LIX y LXI, periodos en los que además el tamaño legislativo de los principales partidos no alcanza diferencias sustanciales (3.06 y 2.99), se acercaban una elecciones y había indisposición entre los agentes para distribuir beneficios entre sí que pudieran romper el equilibrio, lo que se reflejó en la baja emisión de enmiendas proactivas. Sin embargo, durante la LX Legislatura se alcanzó la más alta tasa del NeP (3.55), aunque se emitió una baja cantidad de enmiendas (256), en comparación con la LVIII (781) 
que también coincidió con un inicio de gobierno, lo cual se contrapone con la teoría que postula que la fragmentación del sistema de partidos debilita la base partidista del presidente (Mainwaring \& Shugart, 2002a), ya que se esperaría un incremento en la cantidad de enmiendas efectuadas.

Tabla 6. Modelo de variables vinculadas a la dinámica del sistema de partido y políticocontextuales

\begin{tabular}{|c|c|c|c|c|c|c|}
\hline & Contención & & & Proactivas & & \\
\hline Variables & $B$ & Error típ. & Exp. & $B$ & Error típ. & Exp \\
\hline IOE & $.728^{\star}$ & .445 & 2.072 & $-.174^{\star}$ & .554 & .754 \\
\hline NEP & $2.068^{\star \star}$ & .916 & 7.907 & 1.475 & 1.105 & 4.115 \\
\hline Proximidad ideológica PRI y PAN & $10.876^{* *}$ & 4.406 & $52866, .918$ & $16.686^{\star \star \star}$ & 4.734 & 1764292 \\
\hline $\begin{array}{l}\text { Proximidad ideológica PRD y } \\
\text { partido en el gobierno }\end{array}$ & -.498 & 3.791 & .608 & $-10.750^{* *}$ & 4.823 & 2.144E-00 \\
\hline $\begin{array}{l}\text { Proporción de legisladores de } \\
\text { oposición en comisiones }\end{array}$ & .005 & .005 & 1.005 & $.027^{* * *}$ & .006 & 1.027 \\
\hline Popularidad del presidente & $-6.470^{\star \star \star}$ & 1.770 & .002 & $-8.071^{\star \star}$ & 1.935 & .000 \\
\hline $\begin{array}{l}\text { Luna de miel } \\
2 \text { primeros años + año y medio } \\
\text { posterior a renov. de Congreso }\end{array}$ & $.416^{\star}$ & .229 & 1.516 & $.791^{* *}$ & .256 & 2.206 \\
\hline $\begin{array}{l}\text { Ciclo electoral } \\
\text { Año renovación Congreso }\end{array}$ & .102 & .290 & 1.108 & $-.626^{\star}$ & .342 & .535 \\
\hline $\begin{array}{l}\text { Ciclo electoral } \\
\text { Año renovación Ejecutivo }\end{array}$ & 0 & 0 & 0 & 0 & 0 & 0 \\
\hline Comisiones sector fiscal & .333 & .229 & 1.395 & $.776^{\star * \star}$ & .281 & 2.172 \\
\hline $\begin{array}{l}\text { Comisiones sector derechos, } \\
\text { justicia y gobernación }\end{array}$ & .101 & .309 & 1.107 & .188 & .366 & 1.207 \\
\hline Comisiones issue y Mayores & -.032 & .285 & .968 & $.745^{\star *}$ & .332 & 2.107 \\
\hline Comisiones issue & 0 & 0 & 0 & 0 & 0 & 0 \\
\hline Nagelkerke ,086 & & & & & & \\
\hline
\end{tabular}

Asimismo, la proporción de legisladores de oposición con representación en comisiones muestra una relación significativa positiva con las enmiendas proactivas en ambos modelos. Lo que coincide con la hipótesis de que una mayor representación de legisladores de oposición acrecienta su influencia en los proyectos de ley del Ejecutivo. Como lo muestra la tabla 4, las legislaturas LVII (1997-2000) y LVIII (2000-2003) alcanzaron los rangos más amplios de cambios en la representación de la oposición en comisiones. De igual modo, hubo entonces mayores proporciones de legisladores de oposición en las comisiones clasificadas como fiscales — que además están positivamente relacionadas con la emisión de enmiendas proactivas - y en los periodos legislativos que fueron inicios de mandato presidencial - legislaturas LVIII (2000-2003) y LX (2006-2009)—, factores que causaron el incremento de la emisión de 
enmiendas proactivas. ${ }^{21}$ En concreto, las comisiones en legislaturas de inicio de mandato presidencial tuvieron una tendencia a la proactividad en lo que se refiere a su quehacer legislativo. Mientras que las legislaturas coincidentes con fin de mandato presidencial fueron más proclives a controlar lo solicitado, es decir, a emitir enmiendas de contención.

Estos resultados arrojan información sobre la actuación de los liderazgos partidistas en el Congreso. Una de las facetas del ejercicio de liderazgo partidista en el Congreso se observa en su papel de integrador de comisiones. Los cambios en la composición de las comisiones, mostrados aquí en función de cada comisión específica y por periodo legislativo, reflejan el rol dinámico de los liderazgos partidistas para (re)ubicar a sus agentes en comisiones. Tales cambios de la representación en este nivel cobran especial importancia puesto que podrían ser determinantes en el tipo de dictamen que las comisiones emi$\tan$ y que luego es discutido en el Pleno.

Por su parte, las variaciones en el tipo de enmiendas sugieren que los márgenes para negociaciones posteriores a los acuerdos partidistas adquieren diversas amplitudes. Los hallazgos señalan que dichos liderazgos amplían y restringen los márgenes de negociación —a la luz de las enmiendas - a nivel de y en función de la comisión que analiza una iniciativa y según el contexto político en que se desarrolla el proceso legislativo.

Las variables político-contextuales muestran una dirección en el sentido de las hipótesis planteadas. La popularidad del presidente se relaciona inversamente con las enmiendas de contención y las proactivas. Esto ocurre porque, por lo menos durante el periodo de estudio, los incrementos en la popularidad del presidente están ligados al ciclo electoral, a la proximidad de las elecciones y a las etapas de mayor distanciamiento entre las fuerzas políticas. Los periodos de "luna de miel" y de máxima lejanía de las elecciones, por su parte, se relacionan positivamente con las enmiendas de contención y principalmente con las proactivas. En tanto que el ciclo electoral, en específico el de renovación del Congreso, tiene una significativa relación negativa con las enmiendas proactivas.

La proximidad ideológica entre los principales partidos de oposición con el que se encuentra en el gobierno es un factor con poder explicativo importante acerca del tipo de enmienda. Ello se conjugó con las estrategias legislativas diferenciadas para relacionarse con el gobierno que cada uno de los dos prin-

21 Las legislaturas que empatan con finales de mandato reproducen en las comisiones una representación del bloque opositor similar al de la Cámara: en la LVII (1997-2000) solo dos comisiones tuvieron una representación de partidos de oposición apenas por encima de la proporción de la Cámara; en la LIX (2003-2006) hubo una proporción semejante, y en la LXI (2009-2012) solo dos comisiones presentaron una proporción en la representación del bloque de la oposición ligeramente superior al de la Cámara.

C. Vázquez Ferrel | La influencia legislativa de la oposición en las iniciativas de los gobiernos en minoría en México, 1997-2012 | Perfiles Latinoamericanos, 27(54) | FLACso México | DoI: 10.18504/pl2754-006-2019 
cipales partidos de oposición instrumentó. El gráfico 1 muestra las coaliciones de los partidos que apoyaron las enmiendas a los proyectos de ley examinados en comisiones de la Cámara de Diputados. ${ }^{22}$ Sobresale que la coalición PRDpartido en el gobierno es una de las menos frecuentes en este periodo, lo cual se debió a la poca proximidad ideológica entre uno y otro (véase la tabla 3). En todo caso, la influencia legislativa del PRD se ejerció por la conformación de coaliciones amplias dentro de las comisiones que incluían a los principales partidos de oposición. Esta coalición - tendente a emitir dictámenes con enmiendas de contención y neutrales - ${ }^{23}$ progresivamente perdió peso debido a la polarización ideológica del PRD y su consiguiente alejamiento de la esfera gubernamental, como una estrategia vote-seeking de contraste y confrontación con el presidente instrumentada por ese partido.

\section{Gráfico 1. Coaliciones a nivel de comisiones y tipo de enmienda}

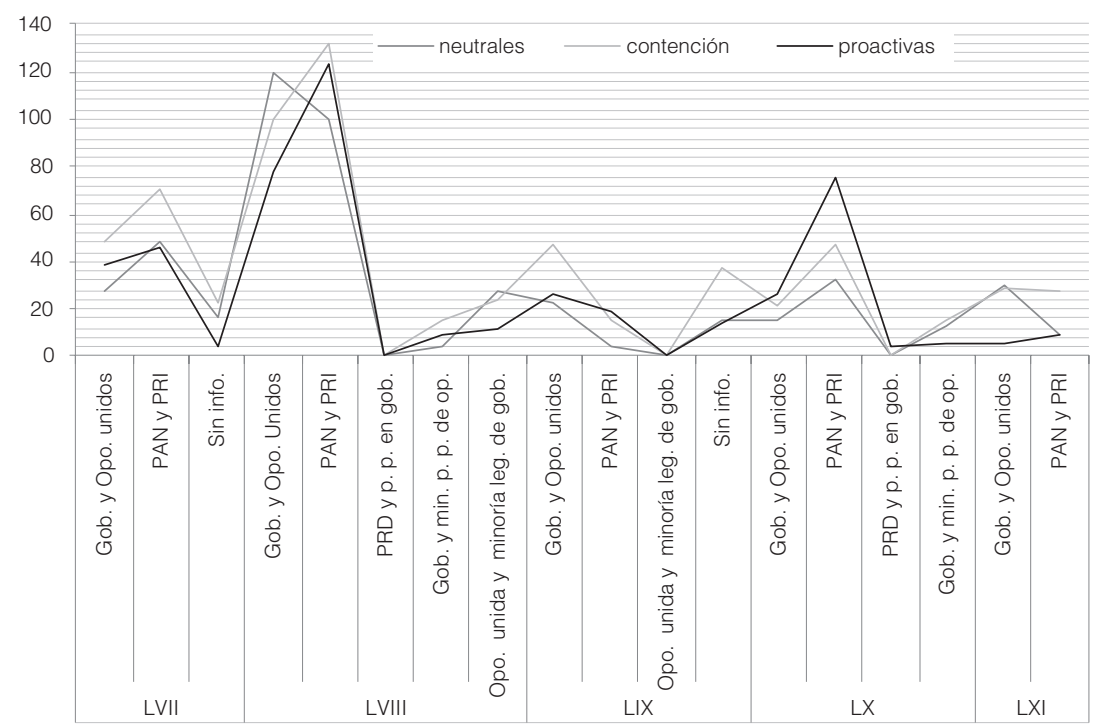

Fuente: Elaboración propia.

22 Se identificó la identidad partidista de los legisladores que firmaron apoyando los dictámenes, o informes, de las comisiones. Se consideró que un partido de oposición apoya el dictamen cuando más del $50 \%$ de sus integrantes en una comisión firma el informe. Cabe agregar que de los 106 proyectos de ley analizados, siete dictámenes no contaron con el respectivo informe disponible con las firmas de los legisladores.

23 Se cambió la categoría de referencia a "proactivas" y los modelos arrojaron para esta variable una relación positiva para la emisión de enmiendas neutrales y de contención. 
Paralelo a este proceso, la conformación de la coalición PRI-partido en el gobierno ${ }^{24}$ incrementó su importancia como una alianza indispensable para lograr que las iniciativas del Ejecutivo superasen la fase de examen y análisis en comisiones. Esta asociación se vinculó estrechamente con la emisión de enmiendas proactivas, reflejo de una estrategia policy-seeking para beneficiar y expandir a sus bases de apoyo político y núcleo de votantes, lo cual fue instrumentado por el PRI como condición para viabilizar la agenda legislativa del Ejecutivo mexicano.

\section{Consideraciones finales}

Frente a los escasos estudios sobre el funcionamiento de los gobiernos en minoría bajo sistemas presidenciales multipartidistas, este trabajo se ha enfocado, primero, en mostrar la evidencia que respalde el argumento de que la influencia ejercida por las agrupaciones de oposición en el Congreso sobre los proyectos de ley del Ejecutivo es uno de los mecanismos que viabiliza la aprobación de la agenda legislativa de estos gobiernos; y, segundo, en aportar un marco analítico tentativo para aproximarnos a la mecánica de la influencia legislativa de la oposición —entendida como las enmiendas impulsadas por estos grupos- sobre las iniciativas del Ejecutivo, a la luz del caso mexicano. Para ello, se mostró el conjunto de enmiendas impulsadas por la oposición en la Cámara de Diputados del Congreso mexicano, clasificándolas según la magnitud de cambio que implicaban. Con esta evidencia, se emprendió un análisis para identificar los factores que incrementan las probabilidades de que se efectúe una determinada enmienda y que pautan la influencia legislativa de la oposición. De este análisis se pueden desprender algunas conclusiones.

Tradicionalmente, se ha percibido a los gobiernos en minoría en sistemas presidenciales en contextos multipartidistas como problemáticos y poco efectivos. Sin embargo, desde una perspectiva numérica, el caso de los gobiernos en minoría mexicanos de los años 1997 a 2012 muestra que entre las fuerzas de oposición y las gubernamentales en el Congreso no surgió una relación legislativa conflictiva. En este análisis ha sido posible verificar que una explicación de la relación fluida entre ambas fuerzas rivales es que los presidentes en minoría en México abrieron el contenido de su agenda impulsada en la Cámara de Diputados a la influencia de las agrupaciones de oposición para conseguir su apoyo y viabilizar la aprobación de su programa de gobierno.

24 Si se consideran todas las iniciativas analizadas para las cuales fue posible recabar dictámenes firmados emitidos por las comisiones, se identifica que el 38\% de los informes fueron firmados por la coalición PAN-PRI, la segunda coalición más numerosa a nivel de comisiones durante el periodo de estudio. 
La influencia legislativa de la oposición a lo largo del periodo en estudio fue intensa y variable por varios motivos. Primero porque la condición de gobierno en minoría colocaba al partido en el gobierno en la imposibilidad de proteger las iniciativas del Ejecutivo de las enmiendas impulsadas por los grupos de oposición. Segundo, dado que las iniciativas del Ejecutivo necesitaban del apoyo de cuando menos uno de los principales partidos de oposición para superar el trámite legislativo, esto los posicionó y dotó de un potencial importante para influir en el contenido de dichas iniciativas.

Uno de los aportes de este trabajo ha sido identificar empíricamente los factores que la literatura destaca en la relación legislativa oposición-gobierno. El NEP es un aspecto relevante, ya que en un sistema integrado por tres partidos con fuerza legislativa similar los agentes legislativos son particularmente sensibles a cambios sutiles en este indicador, puesto que entre más equilibradas son las fuerzas partidistas, son menos proclives para intercambiar beneficios y colaborar. Por otra parte, el IOE mostró que cuando alcanza cifras elevadas, el bloque de la oposición fue sustancialmente fuerte - amplio y cohesionado- y tendió a emitir enmiendas inclinadas a controlar al Ejecutivo. Frente a este escenario, el Ejecutivo refrenó el impulso de su agenda ante los elevados riesgos de sufrir una derrota legislativa en la Cámara. Asimismo, el contexto político mostró una incidencia importante sobre el actuar de las agrupaciones de oposición. Un reducido subconjunto de comisiones tendieron a emitir enmiendas de carácter proactivo, ya fuera cuando actúan por su cuenta o cuando analizaron proyectos de ley en conjunto con otras comisiones, lo que revela las importantes asimetrías de influencia entre comisiones dentro de la Cámara de Diputados. Asimismo, legislaturas de final de mandato presidencial generan un contexto favorable a la emisión de enmiendas tendentes a controlar lo solicitado por el Ejecutivo.

Por otra parte, el factor ideológico es relevante para explicar las variaciones en los tipos de influencia por parte de las agrupaciones de oposición. Cuanto más alejado ideológicamente se encuentre un partido de la oposición, menores probabilidades tendrá de influir en la agenda del Ejecutivo. Siguiendo esta lógica, se puede proponer una hipótesis: la dinámica de los gobiernos en minoría incentiva una política legislativa de cercanía ideológica, ya que al mismo tiempo que castiga al partido más extremo también hace indispensable la colaboración del partido ubicado en torno al centro del continuum ideológico, el cual ejerce una mayor influencia en la agenda del Ejecutivo. Como consecuencia de su participación, este partido de oposición se encuentra en un sitio desde donde da mayor protección y distribuye más beneficios a sus bases de apoyo político y cuenta con más recursos para expandir su núcleo de votantes, lo que incrementa sus aspiraciones reales de llegar al gobierno. 
Pero más allá de los aportes empíricos y teóricos de este artículo, los hallazgos plantean nuevas cuestiones sobre la política legislativa en contextos de gobiernos en minoría en México. Si bien la evidencia numérica respalda el argumento de que estos gobiernos fueron efectivos para desahogar componentes de las agendas legislativas en juego, también cabe esperar que la dinámica que producen los gobiernos en minoría implica negar el apoyo a todo proyecto de ley que amenace con romper el equilibro entre las fuerzas partidistas generándose así una parálisis en la producción de sectores concretos de políticas que puedan producir estos efectos. Otro de los argumentos en este trabajo es que la funcionalidad de los gobiernos en minoría surge de la necesidad por parte de los partidos de oposición de incrementar sus beneficios para distribuirlos entre sus bases de apoyo político y acrecentar su núcleo de votantes. Estos incentivos los llevan a colaborar con el Ejecutivo generándose así una mecánica de intensos intercambios y apoyos mutuos acompasada por el ciclo electoral entre las fuerzas partidistas que viabiliza la aprobación de componentes de sus agendas que satisfagan sus objetivos. La consecuencia lógica de esta mecánica legislativa sería que los gobiernos en minoría favorecen la producción de políticas destinadas a concentrar beneficios particulares y de rendimiento electoral. Verificar la validez de estas cuestiones con información detallada que incluyan un mayor número casos será esencial para mejorar nuestro entendimiento sobre algunos de los costos del funcionamiento de los gobiernos en minoría.

\section{Referencias}

Alemán, E. \& Calvo, E. (2007). Analyzing Legislative Success in Latin America: The Case of Democratic Argentina. En G. O’Donell, J. Tulchin, A. Varas \& A. Stubits (Eds.), The Study of New Democracies in Latin America (pp. 7-37). Woodrow Wilson Institutional Center for Scholars. Latin American Program.

Alemán, E. \& Tsebelis, G. (2011). Political Parties and Government Coalitions in the Americas. Journal of Politics in Latin America, 3(1), 3-28.

Altman, D. \& Pérez-Liñán, A. (1999). Más allá de la poliarquía: una aproximación a la calidad de las democracias. Revista Uruguaya de Ciencia Politica, (11), 83-105.

Amorim Neto, O. (2006). Presidencialismo e Governabilidade nas Américas. Río de Janeiro: FGv/ Konrad Adenauer.

Amorim Neto, O. \& Santos, F. (2012). The Inefficient Secret Revisted: The Legislative Input and Output of Brazilian Deputies. Legislative Studies Quarterly, 28(4). 
Amorim Neto, O., Cox, G. W. \& McCubbins, M. D. (2003). Agenda Power in Brazil's Câmara Dos Deputados, 1989-98. World Politics, 55(4), 550-578.

Axelrod, R. (1986). La evolución de la cooperación: El dilema del prisionero y la teoría de juegos. Madrid: Alianza Editorial.

Barrett, W. A. \& Eshbaugh-Soha, M. (2007). Presidential Success on the Substance of Legislation. Political Research Quarterly, 60(1), 100-112.

Béjar, L. (2003). Representación Parlamentaria y Disciplina Partidista: el caso México. En R. M. Mirón \& L. Béjar (Eds.), El Congreso Mexicano después de la Alternancia (pp. 197-221). México: Asociación Mexicana de Estudios Parlamentarios/Senado de la República.

Bonvecchi, A. \& Zelaznik, J. (2010). Measuring Legislative Input on Presidential Agendas. Ponencia presentada en el Congress of the Latin American Studies Association, 6-9 de octubre. Toronto, Canadá.

Budge, I. \& Laver, M. (1986). Office Seeking and Policy Pursuit in Coalition Theory. Legislative Studies Quarterly, 11(4), 485-506.

Calvo, E. (2007). The Responsive Legislature: Public Opinion and Law Making in a Highly Disciplined Legislature. British Journal of Political Science, 37(2), 263-280.

Cámara de Diputados. Datos consultados entre el 1 de septiembre y 15 de diciembre de 2012, en http://www.diputados.gob.mx

Campos, R. (2012). El Juicio Ciudadano. Evaluación de la Presidencia de Felipe Calderón en México 2006-2012. México: Consulta Mitofsky.

Casar, A. M. (2013). Quince años de gobiernos sin mayoría en el Congreso mexicano. Política y Gobierno, XX(2), 219-263.

Casar, A. (2002). Perspectivas Políticas de un Gobierno Dividido en México. En M. A. Casar \& I. Marván (Eds.), Gobernar sin mayoría. México 1867-1997. México: CIDE/Taurus.

Chasquetti, D. (2008). Democracia, presidencialismo y partidos políticos en América Latina: Evaluando la «dificil combinación». Montevideo: Instituto de Ciencia Política, Facultad de Ciencias Sociales, Universidad de la República.

Cheibub, J. A. (2007). Presidentialism, Parliamentarism, and Democracy. Cambridge: Cambridge University Press. 
Cheibub, J. A., Przeworski, A. \& Saiegh, S. M. (2004). Government Coalitions and Legislative Success Under Presidentialism and Parliamentarism. British Journal of Political Science, 34(4), 566-587.

Colomer, J. M. \& Negretto, G. L. (2003). Gobernanza con poderes divididos en América Latina. Politica y Gobierno, X(1), 13-61.

Colomer, J. M. \& Negretto, G. L. (2005). Can presidentialism work like parliamentarism? Government and Opposition, (40), 60-89.

Cox, G. \& Morgenstern, S. (2001). Latin America's Reactive Assemblies and Proactive Presidents. Comparative Political Studies, 33(2), 171-189.

Deheza, G. I. (1998). Gobiernos de Coalición en el Sistema Presidencial: América del Sur. En N. Dieter \& M. Fernández (Eds.), El Presidencialismo renovado. Instituciones y cambio político en América Latina (pp. 151-169). Caracas: Nueva Sociedad.

Dominguez, C. B. K. (2001). Is it a honeymoon? An Empirical Investigation of the President's First Hundred Days. Congress \& the Presidency, (32), 63-78.

Edwards III, G. C. \& Barrett, A. (1999). Presidential Agenda Setting in Congress. En Congress and the President in a Partisan Era (pp. 206-209). Program in American Politics in the Center for Presidential Studies.

García. F. \& Martínez, B. E. (2002). La estrategia política y parlamentaria de los partidos de oposición latinoamericanos: ¿capacidad de influencia o influencia efectiva? Instituciones y Desarrollo, (12-13), 331-373.

Fernandez-Albertos, J. \& Lapuente, V. (2010). Doomed to disagree? Party-voter discipline and policy gridlock under divided government. Party Politics, 17(6), 801-822.

Figueiredo, A., Vieira, M. \& Canello, J. (2012). Governos Minoritários no Presidencialismo Latino-Americano: Determinantes Institucionais e Políticos. Dados-Revista de Ciências Sociais, (55), 839-875.

García Montero, M. (2009). Presidentes y Parlamentos: ¿quién controla la actividad legislativa en América Latina? Madrid: Centro de Investigaciones Sociológicos.

Haggard, S. \& Shugart, M. D. (2001). Institutions and Public Policy in Presidential Systems. En S. Haggard \& M. D. McCubbins (Eds.), Presidents, Parliaments and Policy (pp. 64-104). Nueva York: Cambridge University Press. 
Laakso, M. \& Taagepera, R. (1979). Effective Number of Parties: A Measure with Application to West Europe. Comparative Political Studies, 12(1), 3-27.

Laver, M. \& Shepsle, K. A. (2012). Coalitions and cabinet government. The American Political Science Review, 84(3), 873-890.

Light, C. P. (1999). The President's Agenda. Domestic Policy Choice from Kennedy to Clinton. Baltimore, Maryland: The Johns Hopkins University Press.

Linz, J. (1990). The Perils of Presidencialism. Journal of Democracy, 1(1), 51-69.

Lujambio, A. (Ed.). (1996). Poder Legislativo. Gobiernos divididos en la Federación Mexicana. México: Uam/Ife/Colegio de Ciencias Políticas y Administración.

Mainwaring, S. \& Shugart, M. (2002a). Presidencialismo y sistema de partidos. En S. Mainwaring \& M. Shugart (Eds.), Presidencialismo y democracia en América Latina (pp. 254294). Buenos Aires: Paidós.

Mainwaring, S. \& Shugart, M. (2002b). Presidencialismo y democracia en América Latina. Buenos Aires: Paidós.

Masters, N. A. (1961). Committee Assignments in the House of Representatives. The American Political Science Review, 55(2), 345-357.

Mejía Acosta, A. \& Polga-Hecimovich, J. (2011). Coalition Erosion and Presidential Instability in Ecuador. Latin American Politics and Society, 53(2), 87-111.

Mezey, M. (1979). Comparative legislatures. Durham: Duke University Press.

Morgenstern, S., Javier Negri, J. \& Pérez-Liñán, A. (2008). Parliamentary Opposition in NonParliamentary Regimes: Latin America. The Journal of Legislative Studies, 14(1-2), 160-189.

Müller, W. C. \& Strøm, K. (1999). Policy, Office, or Votes? How Political Parties in Western Europe Make Hard Decisions. Cambridge: Cambridge University Press.

Mustapic, A. \& Goretti, M. (2012). Gobierno y oposición en el Congreso: La práctica de la cohabitación durante la presidencia de Alfonsín (1983-1989). Desarrolllo Económico, 32(126), 251-269.

Nacif, B. (2002). Understanding Party Discipline in the Mexican Chamber of Deputies: the centralized Party Model. En S. Morgenstern \& B. Nacif (Eds.), Legislative Politics in Latin America (pp. 254-284). Nueva York: Cambridge University Press. 
Nacif, B. (2000). El sistema de comisiones permanentes en la Cámara de Diputados de México. En G. Pérez \& A. Martínez (Eds.), La Cámara de Diputados en México. México: Flacso México/Cámara de Diputados del H. Congreso de la Unión/M. Á. Porrúa.

Neustadt, R. E. (1960). Presidential Power and the Mondern Presidents. The Politics of Leadership from Roosevelt to Reagan. Nueva York: The Free Press.

Payne, J. M. \& Zovatto, G. D. (2003). La politica importa: democracia y desarrollo en América Latina. Washington, D. C.: Banco Interamericano de Desarrollo.

Pfiffner, J. (1992). The President and the Postreform Congress. En R. Davidson (Ed.), The Postreform Congress (pp. 211-232). Nueva York: St. Martins Press.

PNUD. (2004). La democracia en América Latina: Hacia una democracia de ciudadanas y ciudadanos. Buenos Aires: PNUD.

Powell, G. (1991). Divided Government as a Pattern of Governance. Governance, 4(3), 231-235.

Raile, E. D., Pereira, C. \& Power, T. J. (2010). The Executive Toolbox: Building Legislative Support in a Multiparty Presidential Regime. Political Research Quarterly, XX(X), 1-12.

Samuels, D. \& Shugart, M. (2003). Presidentialism, Elections and Representation. Journal of Theoretical Politics, 15(1), 33-60.

Sani, G. \& Sartori, G. (1980). Polarización, Fragmentación y Competición en las Democracias Occidentales. Revista del Departamento de Derecho Político, (7), 7-37.

Scartascini, C., Spiller, P., Stein, E. \& Tommasi, M. (2010). El juego politico en América Latina ¿Cómo se deciden las políticas públicas? Washington, D. C.: Banco Interamericano de Desarrollo.

Scartascini, C., Stein, E. \& Tommasi, M. (2010). How democracy works. Political institutions, actors, and arenas in Latin American Policymaking. Cambridge: Inter-American Development Bank/David Rockerfeller Center.

Shepsle, K. A. \& Weingast, B. R. (1981). Structure-induced equilibrium and legislative choice. Public Choice, (37), 503-519.

Shugart, M. \& Carey, J. (1992). Presidents and Assemblies. Constitutional Design and Electoral Dynamics. Nueva York: University of Cambridge. 
Siavelis, P. M. (2003). The President and Congress in Postauthoritarian Chile. Institutions Constraints to Democratic Consolidation. University Park, Pennsylvania: The Pennsylvania State University.

Sistema de Información Legislativa (sIL). Datos consultados entre el 1 de septiembre y 15 de diciembre de 2012, en http://sil.gobernacion.gob.mx/portal

Strøm, K. (1991). Minority Government and Majority Rule. Nueva York: Cambridge University Press.

Toro Maureira, S. \& Hurtado, N. (2010). Enmiendas y proceso legislativo: Influencia, coordinación $y$ delegación partidaria en el Congreso chileno. Ponencia presentada en el Congress of the Latin American Studies Association, 6-9 de octubre. Toronto, Canadá.

Tsebelis, G. (2006). Jugadores con veto. Cómo funcionan las instituciones políticas. México: FCE.

Weldon, J. A. (2002). Las estrategias presidenciales con gobierno dividido en México, $1917-$ 1937. En M. A. Casar \& I. Marván Laborde (Eds.), Gobernar sin mayoría. México 18671997. México: CIDE/Taurus.

Zechmeister, E. J. (2010). Left-Right Semantics as a Facilitator of Programmatic Structuration. En H. Kitschelt, K. A. Hawkins, J. P. Luna, G. Rosas \& E. J. Zechmeister (Eds.), Latin American Party Systems (pp. 96-118). Nueva York: Cambridge University Press.

\section{Anexo 1 \\ Clasificación de enmiendas con base en Barrett \& Eshbaugh-Soha (2007) ajustado para esta investigación}

\begin{tabular}{|c|c|c|}
\hline $\begin{array}{l}\text { Clarificaciones: } \\
\text { técnica legislativa, } \\
\text { plazos incluidos } \\
\text { en transitorios y } \\
\text { adaptaciones al } \\
\text { marco general } \\
\text { afectado por } \\
\text { la propuesta } \\
\text { legislativa. }\end{array}$ & $\begin{array}{l}\text { Intensidad: estas enmiendas modi- } \\
\text { fican, exclusivamente, la intensidad } \\
\text { de los cambios propuestos en la } \\
\text { iniciativa original enviada por el } \\
\text { Ejecutivo, pero no buscan alterar } \\
\text { la dirección de los cambios, ni } \\
\text { modificar el foco de actores al que } \\
\text { va dirigida la política pública. } \\
\text { Supresión: estas enmiendas van } \\
\text { desde proponer la cancelación de } \\
\text { algunos incisos o algún artículo, } \\
\text { hasta plantear eliminar un conjunto } \\
\text { de artículos o título completo del } \\
\text { proyecto de ley. } \\
\vdots \\
\vdots \\
\vdots \\
\vdots\end{array}$ & $\begin{array}{l}\text { Foco de acción: este tipo de enmiendas implican } \\
\text { modificar la amplitud de los actores políticos o sectores } \\
\text { a los que afecta o beneficia la iniciativa propuesta por } \\
\text { el Ejecutivo. } \\
\text { Transformadoras: estas enmiendas modifican tanto el } \\
\text { tipo de actores o sectores sobre los que se quiere influir, } \\
\text { así como la dirección de los cambios propuestos en la } \\
\text { iniciativa del Poder Ejecutivo. } \\
\text { Adicionan y sustituyen: estas enmiendas proponen la adi- } \\
\text { ción o sustitución de algún artículo o inciso en concreto, } \\
\text { o también de títulos. } \\
\text { Relativas a otros aspectos: son enmiendas propuestas } \\
\text { que aluden a materias o actores que no están directa- } \\
\text { mente comprendidas en la iniciativa propuesta. } \\
\vdots \\
\vdots\end{array}$ \\
\hline Neutrales & Contención & Proactivas \\
\hline
\end{tabular}

